\section{Reconfigurações do público e do privado: mutações da sociedade tecnológica contemporânea}

\section{RESUMO}

Este texto investiga a alteração da dialética público/privado, que marcara a modernidade, no cenário da sociedade tecnológica contemporânea. A partir das teses de Richard Sennett, postas em diálogo com a analítica do poder foucaultiana, a modernidade é caracterizada segundo dois eixos centrais: privilégio do espaço privado sobre a esfera pública, propriamente política, e consolidação de certa experiência de si como interioridade. Nesta virada de século, delineiam-se o declínio de tal experiência de si e a correlata dissolução da nítida fronteira anteriormente traçada entre as esferas do público e do privado, tanto sob a forma da crescente privatização do espaço público quanto da emergência de novas formas de autotematização, de sociabilidade e de percepção de mundo. Como objeto de investigação, privilegia-se uma recente exposição de projetos arquitetônicos de moradias, no MOMA de Nova York, intitulada "A casa nãoprivada".

\section{ABSTRACT}

This text discusses the change ocurred in the dialectical opposition between the concepts of public and private which have marked modernity in the realm of our contemporary technological society. As an illustration of the discussion, it was chosen a recent architectural exhibition held at the MOMA of New York, entitled "The non-private home".

\section{PALAVRAS-CHAVE/KEY-WORDS}

- Sociedade tecnológica (Technological society)

- Pós-modernidade (Postmodernity)

- Arquitetura (Architecture)

\section{Maria Cristina Franco Ferraz}

Prof. Dra. Universidade Federal Fluminense
DiVERSOS AUTORES TÊM assinalado, recentemente, a crise da dicotomia, característica da modernidade, entre público e privado como um dos vetores através dos quais podem ser pensadas as mutações da atual sociedade tecnológica. Na conhecida tese exposta por Richard Sennett em meados da década de $70,{ }^{1}$ a paulatina instauração da distância e da cisão entre as esferas do público e do privado é minuciosa e sutilmente investigada a partir da passagem do século XVIII para o XIX. As grandes cidades em expansão, sobretudo Paris e Londres, são, nesse texto, o palco no qual se ensaiam e se efetuam transformações nas complexas formas de sociabilidade vinculadas ao avanço do capitalismo e à estabilização das camadas médias da sociedade. Sennett associa certo esvaziamento da esfera pública e propriamente política - com sua lógica calcada no valor da arte, do artifício e das máscaras nas interações humanas - ao regime da "autenticidade", baseado na crença na personalidade como um interior que inexoravelmente se trai em sua apresentação pública e que, portanto, deve se proteger constantemente de sua insistente expressividade. Ao regime da máscara que se afirmava como tal passou-se, então, ao da máscara que esconde um rosto por demais involuntariamente "verdadeiro" para ser exposto, sem anteparos, ao olhar penetrante e devassador de estranhos. Ao mesmo tempo em que se introduz a lógica do consumo de massa e que se instala o fetichismo da mercadoria, nas grandes metrópoles do século XIX passa-se a adotar, publicamente, uma atitude de passividade, voyeurismo e contemplação; seus habitantes tendem assim a afastar-se radical- 
mente das formas ativas de sociabilidade próprias ao regime do "homem como ator" que, segundo o sociólogo, caracterizava as interações nas capitais européias do século XVIII.

Na modernidade, emerge, assim, o paradigma das "tiranias da intimidade", analogamente apontado por Michel Foucault, também em meados dos anos 70, na parte de sua obra dedicada à análise das relações de poder nas sociedades capitalistas modernas, sobretudo no primeiro volume de sua História da sexualidade. ${ }^{2}$ Em certo sentido, as teses de Sennett e de Foucault dialogam e se complementam, na medida em que o filósofo francês, retomando a "genealogia da interioridade" inaugurada por Nietzsche no final do século XIX, ressalta de que forma as práticas de produção de verdade modernas vinculam-se às estratégias da sociedade disciplinar e a certa laicização da prática da confissão, nas ciências humanas produzidas na virada do século XIX para o XX, configurando um tipo de homem que não cessa de se auto-examinar, de perscrutar sua "interioridade", buscando-lhe a chave interpretativa no âmbito do vasto e inesgotável campo do desejo. Como escreve Foucault, tornamo-nos, no século XX, uma sociedade eminentemente "confessanda":

"A confissão difundiu amplamente seus efeitos: na justiça, na medicina, na pedagogia, nas relações amorosas, na esfera mais cotidiana e nos ritos mais solenes; confessam-se os crimes, os pecados, os pensamentos e os desejos; confessam-se passado e sonhos, confessa-se a infância; confessam-se as próprias doenças e misérias; emprega-se a maior exatidão para dizer o mais difícil de ser dito; confessa-se em público, em particular, aos pais, aos educadores, ao médico, àqueles a quem se ama; fazemse a si próprios, no prazer e na dor, confissões impossíveis de confiar a outrem, com o que se produzem livros". ${ }^{3}$

A verdade daquilo que somos passa a se instalar, portanto, definitivamente, na "in- terioridade", percebida e vivida como a instância que determina nosso ser, cuja chave de acesso, conceitualizada pelas novas ciências da alma (psicologia e, sobretudo, psicanálise), é cada vez mais remetida ao "desejo" a ser insistentemente perseguido, investigado e laboriosamente interpretado. Como bem mostra Foucault igualmente em $A$ verdade e as formas jurídicas, nas sociedades disciplinares modernas não são mais os atos, a exterioridade das ações - portanto, o campo propriamente político - que define o que somos, "quem" somos, mas, antes, a instância privada da interioridade. Assim, tanto Foucault quanto Sennett, com suas obras, colaboram para o que poderíamos caracterizar como uma "história política da interioridade", mostrando de que maneira o privilégio da "intimidade", percebida e sentida como mais autêntica e verdadeira do que a esfera do público, correspondeu, na modernidade, a um progressivo esvaziamento do campo do político como lugar de exercício e de produção daquilo que se é. Apenas para assinalar de que forma tal tendência se torna mais do que evidente nas sociedades contemporâneas, basta mencionar a relevância conferida, atualmente, ao comportamento "privado" - geralmente de âmbito sexual - de personalidades políticas. O exemplo desse foco "privatizante" em pleno campo do imediatamente político que, de saída, nos vem à lembrança - em virtude de sua imensa repercussão (e, é claro, produção) midiática - é, obviamente, o caso Bill Clinton/Mônica Lewinsky. Para ilustrar brevemente de que forma a confissão laicizada funciona atualmente como técnica privilegiada de produção de verdade e de sociabilidade, que configura as "tiranias da intimidade", basta também lembrar o último filme, inacabado, de Stanley Kubrick, "De olhos bem fechados", no qual os dramas vividos pelo personagem principal giram em torno de uma pequena "confissão" de sua mulher. Outro aspecto não menos relevante do privilégio do privado sobre o público, que, instalado no século XIX, se estende à contemporaneidade e nela se intensifica, corresponde a já assinalada privatização dos espaços públicos 


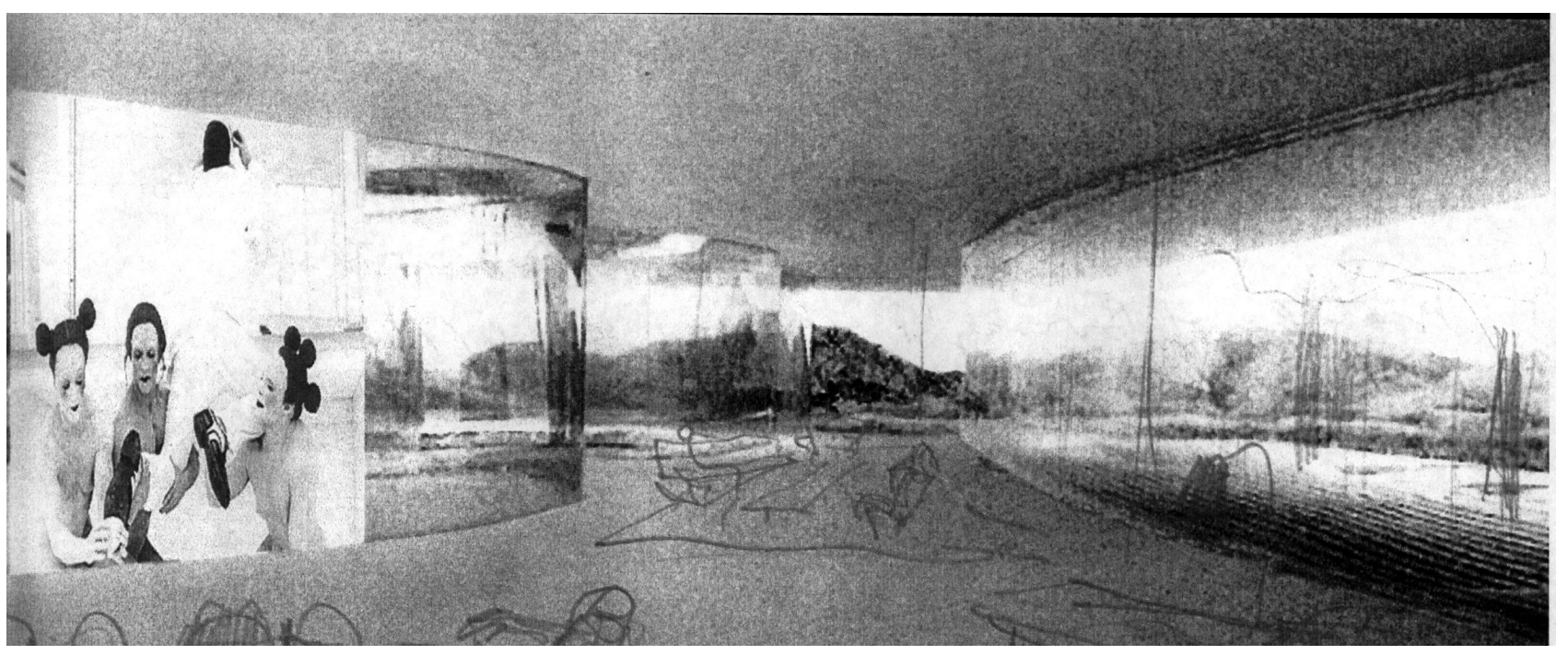

Ground-floor interior with Matthew Barney's Cremaster 4. (1995-96) video instalation at left. (imagem gerada por computador).

característica da urbanização de certas cidades ou bairros, como nos casos de Los Angeles, Brasília e do bairro da Barra da Tijuca, no Rio de Janeiro. Vários autores e pesquisadores têm ressaltado o fechamento e insulamento característicos desses locais, nos quais as ruas - antigos espaços de trocas e de inesperadas interações sociais - se esvaziam de pedestres, em que se privilegia o transporte privado - a não ser, como na Barra da Tijuca, para as classes trabalhadoras -, as moradias se confinam em condomínios cada vez mais polivalentes e auto-suficientes e os shoppings se tornam locais hegemônicos de consumo e lazer. Como uma contraprova do aspecto "privatizante" de tais espaços, mencionemos a nova estratégia política de certos segmentos sociais brasileiros, organizados em movimentos como os sem-terra e sem-teto, que recentemente invadiram, com seus corpos excluídos dos prazeres do capitalismo, esses novos templos do consumo, revelando, de forma evidente, o aspecto político, a violenta segregação social implicada nesse fenômeno de privatização dos espaços públicos, cada vez mais presente nas formas urbanas atuais.

A simples alusão a tais fatos e aspectos indica, por si só, a expansão do campo do "privado" e o crescente esvaziamento do espaço público, que têm sido apontados como característicos das megalópoles contemporâneas. Nesse sentido, podemos afirmar que, se a cisão entre público e privado correspondeu ao desenvolvimento das sociedades industri- ais modernas, a que se vincula, por sua vez, a consolidação dos Estados-nação, pode-se observar o paulatino esgarçamento dessa dicotomia nas grandes cidades contemporâneas, por conta da expansão cada vez mais evidente do campo do "privado" em detrimento do espaço público. Evidentemente, esse fenômeno encontra-se articulado às mutações do capitalismo no final do século XX que alguns autores identificam como "pósindustrial" ou "tardio" -, caracterizado, fundamentalmente, pela preponderância do capital financeiro transfronteira sobre o capital aplicado à produção de bens e por um efeito de radical virtualização do valor, tanto em um sentido estritamente monetário quanto de forma mais geral. ${ }^{4}$ Nesse sentido, ainda, assinalem-se as recentes reflexões de pensadores como Michael Hardt e Antonio Negri ${ }^{5}$, que discutem a expansão do "império" capitalista, a partir da queda do muro de Berlim, e a conseqüente derrocada da distinção entre "dentro" e "fora", entre "público" e "privado", caracterizando-se a forma imperial contemporânea por uma lógica de "inclusão" que pretende abarcar todo o planeta, não sem produzir, simultaneamente, zonas de exclusão cada vez mais abrangentes, podendo essas corresponder tanto a bolsões de miséria no entorno das próprias regiões de opulência quanto a continentes inteiros, como é o caso do continente africano.

Se podemos, portanto, estabelecer certa linha de continuidade entre a tendência mo- 


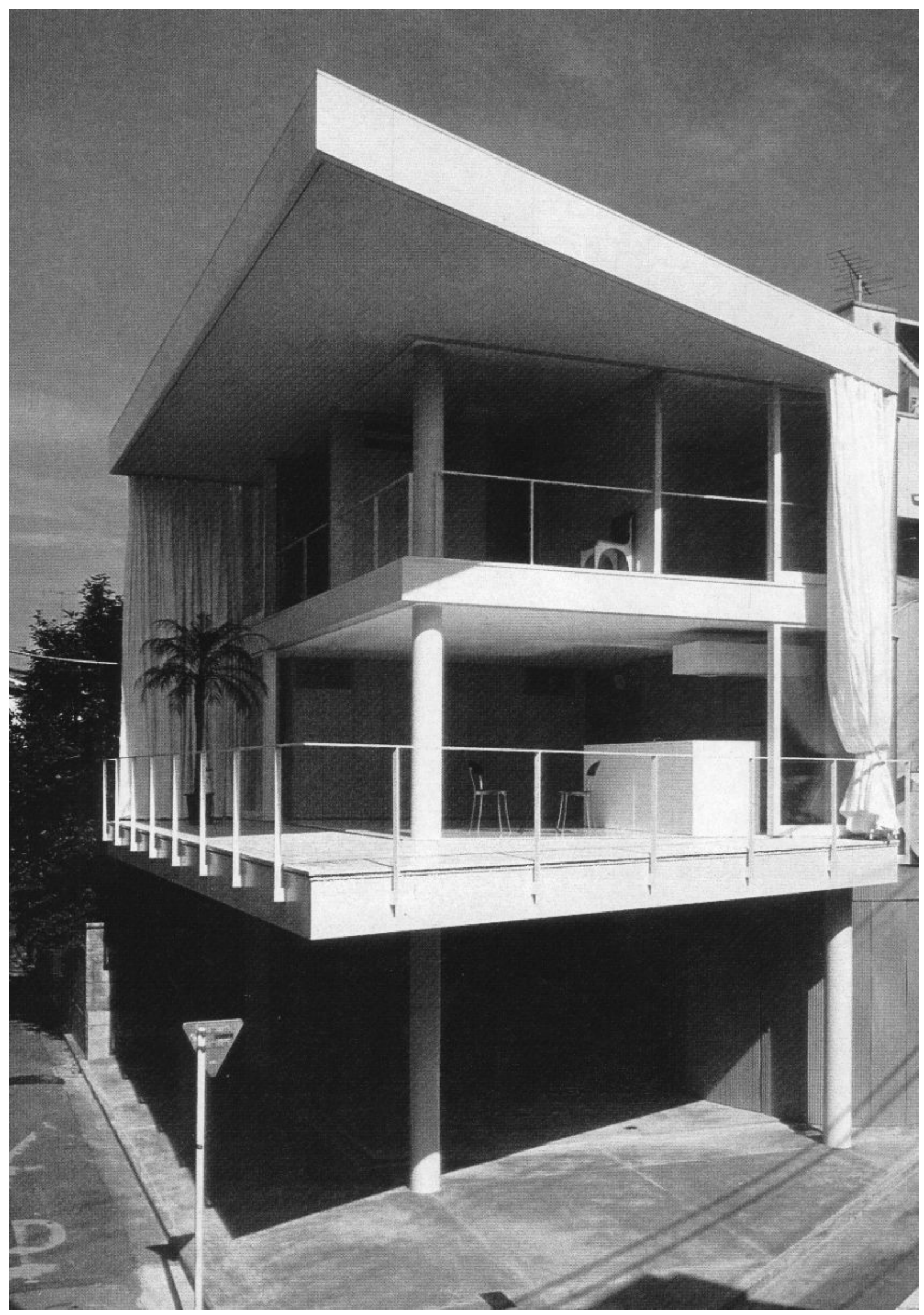

Shigeeru Ban: Curtain Wall House. Tokyo, 1995. 
derna à ênfase no privado em detrimento do público e a progressiva privatização dos espaços públicos/políticos própria à contemporaneidade, cabe assinalar uma importante transformação que se está produzindo no campo da subjetividade, no que diz respeito ao regime $\mathrm{da}$ "interioridade" associado àquele processo. Em recente grupo de trabalho com filósofos, psicanalistas e psiquiatras de que participei ${ }^{6}$, o professor e psicanalista Benílton Bezerra Júnior (UERJ) ressaltou o evidente declínio, nos últimos vinte e cinco anos, do paradigma da interioridade, em virtude dos recentes avanços da psicopatologia psiquiátrica. Segundo Benílton, tal paradigma atravessou pelo menos os dois últimos séculos e o século XX pode ser caracterizado como a era do homem freudiano, que se definia pela interioridade e cuja experiência de si se encontrava referida à idéia de conflito.

Freud teria, nesse sentido, refletido tal cultura e a catapultado à sua máxima expressão. As mudanças que, nas últimas décadas, têm afetado o quadro cultural mais amplo alterando as próprias noções de vida, de individualidade e de sofrimento - expressamse igualmente na atual negação da interioridade, em favor de explicações de cunho "fisicalista" que se introduzem nos campos da psiquiatria e até mesmo no da psicanálise. Nesses campos, tende-se cada vez mais a privilegiar a mera descrição de sintomas: o que anteriormente era tematizado como conflito e favorecia a experiência trágica passa a ser tratado, antes, sob o modo da disfunção, da anomalia a ser corrigida por meio de uma psicofarmacologia em franco desenvolvimento. Tais medicamentos têm seu valor associado à rapidez e eficiência na eliminação dos sintomas do mal-estar contemporâneo, tratando-se de um negócio extremamente lucrativo que tem movido cifras astronômicas: em dados de cinco anos atrás, segundo Benílton Bezerra, o medicamento antidepressivo Prozac, por exemplo, gerou sete bilhões de dólares. Esvazia-se assim, progressivamente, a tragicidade da experiência humana, vinculada, na modernidade, à autotematização do homem como interioridade. Na contempora- neidade, delineia-se, antes, um cenário no qual ganham um espaço cada vez maior ideologias cientificistas ligadas à atual agenda das neurociências e das biotecnologias, que priorizam resultados mais "eficazes", imediatos, indolores, supostamente mais aptos a eliminar a nova sintomatologia do mal-estar, seja sob a forma de depressões ou das novas fobias sociais, como a síndrome do pânico. $\mathrm{O}$ critério mesmo de "normalidade" passa a ser cada vez mais referido à adequação a modelos de performance física e mental. A própria idéia de vida, anteriormente associada à natureza e, portanto, simples e intuitiva, passou a ser uma complexa questão em aberto, um problema científico, ético e político sobre o qual é necessário argumentar.

Se Foucault caracterizou argutamente o poder capitalista moderno como um biopoder, na medida em que, à diferença das sociedades de soberania, ele se ocupa da gestão de corpos e das vidas de todos os indivíduos, caberia então hoje pensar, como fazem Jurandir Freire Costa e Benílton Bezerra, em uma "biopolítica", em termos de "biossociabilidade", uma vez que é sobre a própria "vida" que passam a incidir as relações de poder.

Se podemos, portanto, pensar a contemporaneidade a partir de certos traços característicos assinalados tanto por Foucault quanto por Sennett como próprios à modernidade, em nossas investigações acerca da sociedade tecnológica contemporânea devemos, entretanto, estar igualmente atentos à observação de um quadro em mutação. A partir dessas breves indicações iniciais, pretendo explorar certos aspectos dessas transformações, vinculando-as à crescente disseminação de novas tecnologias no cotidiano das megalópoles contemporâneas, tomando como objeto de investigação uma recente exposição de projetos arquitetônicos, apresentada de julho a outubro de 1999 no Museu de Arte Moderna de Nova York. Significativamente, a exposição chamava-se "The Un-private house" ("A casa não-privada"). Como evidenciado no próprio título, tratava-se de projetos arquitetônicos - muitas vezes autodenominados "pós-modernos" - que revelam claramente uma ten- 


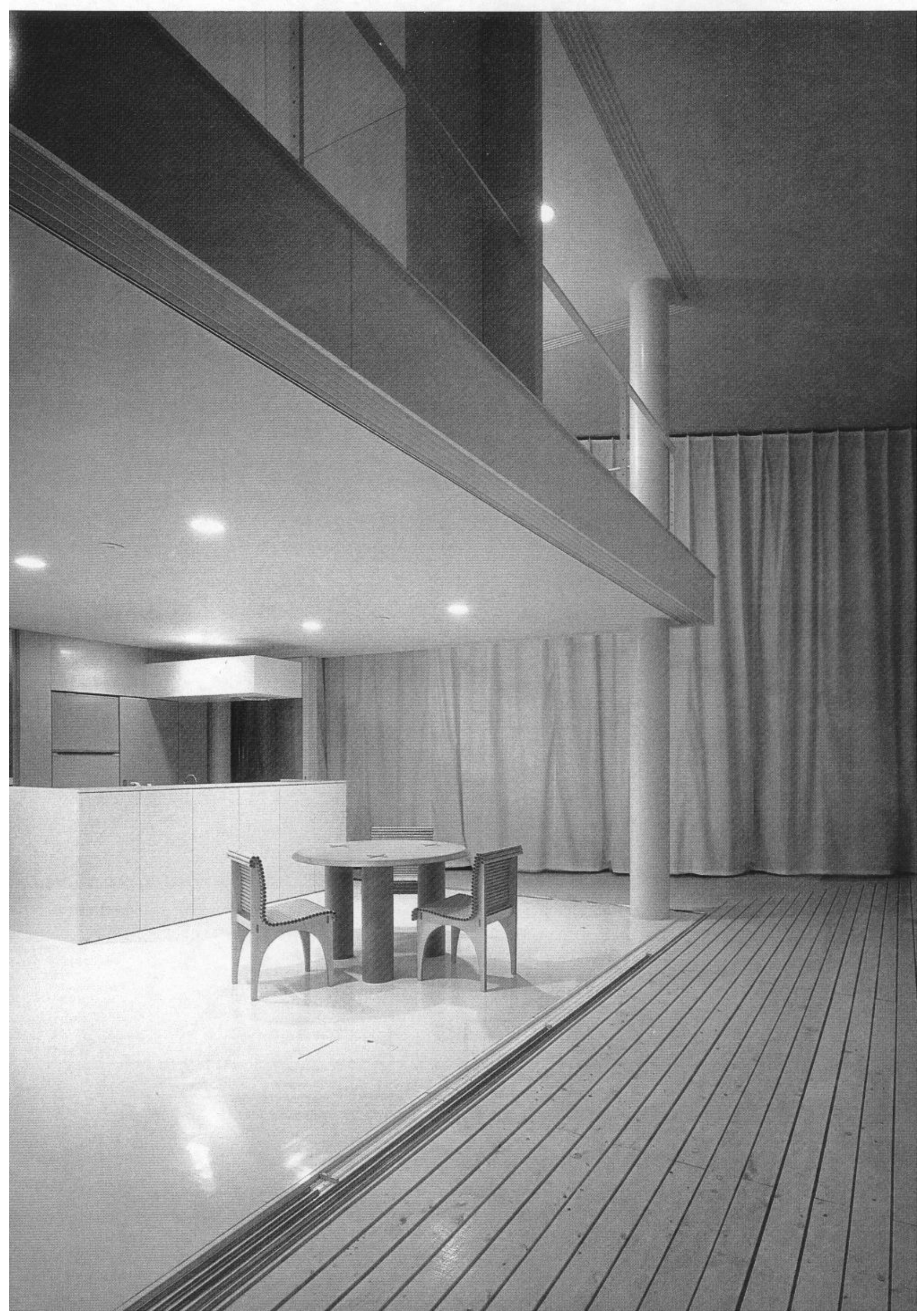

Curtain Wall House: Living area and terrace. 
dência que aponta para a falência da dialética público-privado, no caso, justamente, de projetos de moradias. Ainda que os projetos expostos estivessem longe de se pretenderem majoritários, tendo sido em grande parte encomendados por certos clientes provenientes das camadas privilegiadas de países ricos e desenvolvidos (especialmente Estados Unidos e Japão), eles não deixam de ser significativos para nosso tema, sobretudo se, inspirados em Foucault, pensarmos as casas como dispositivos arquitetônicos que funcionam tanto como efeito quanto como instrumento de produção de novos modos de subjetivação. Assim como, para pensar as relações efetivas de poder nas sociedades capitalistas modernas, Foucault privilegiou o projeto arquitetônico panóptico criado por Jeremy Bentham - que de fato se disseminou pelas mais variadas instituições disciplinares -, talvez possamos partir dos projetos de ponta apresentados na exposição para vislumbrarmos o tipo de subjetividade e as formas de sociabilidade que tendem a se constituir no contexto das sociedades capitalistas altamente desenvolvidas.

No texto introdutório ao catálogo da exposição ${ }^{7}$, que tomarei aqui muitas vezes como fonte, o curador Terence Riley afirma que as condições sociais e estruturais que levaram, ao longo dos últimos quatrocentos anos e especialmente a partir do início do século XIX, ao desenvolvimento da "casa privada" - família mononuclear burguesa, separação entre os mundos do trabalho e da vida, ideais de domesticidade e de privacidade em relação ao público - têm-se alterado drasticamente nas últimas décadas. Como evidência de tais transformações, menciona, por exemplo, o fato de que, atualmente, pessoas morando sozinhas ou apenas com uma outra são maioria em diversas partes do mundo industrializado. No caso dos Estados Unidos, aproximadamente um quarto das residências americanas era, em dados de 1999, ocupado apenas por uma pessoa e metade das famílias americanas composta por casais sem filhos, vivendo sob o mesmo teto. $\mathrm{O}$ curador arrisca, então, apoiado em pesquisas recentes, o prognóstico de que a maioria dos ame- ricanos irá muito em breve provavelmente passar grande parte de suas vidas sozinhos ou com um companheiro, mas não necessariamente com crianças. ${ }^{8}$ Essas novas circunstâncias têm alterado certas necessidades em função das quais as casas eram projetadas, tais como a importância da privacidade visual e acústica, no caso de haver crianças em casa, e da usual separação entre o andar de cima e o andar de baixo (típica das tradicionais casas de classe média americana), que demarcava a divisão entre o espaço público, de reunião de todos e de recepção de pessoas de fora, e o espaço privado, propriamente doméstico. Diante essa nova situação, o modelo do "loft" parece, segundo Riley, predestinado a ser o mais apropriado, oferecendo flexibilidade e abertura, em expressivo contraste com os espaços estruturados típicos das casas da família tradicional. ${ }^{9}$ Como exemplos desse tipo de espaço semelhante ao de lofts, o curador cita dois projetos desenhados para jovens casais sem filhos: uma residência em Beverly Hills construída para um casal gay e uma casa em Houston, projetada para uma mulher divorciada cujos filhos já se tornaram adultos. A propósito de uma moradia já construída nesses termos em Atlanta, o proprietário relata que, por ocasião da primeira visita de seus pais à casa, precisou explicar à sua mãe que, em vez de quartos, em sua nova casa só havia "situações". Tanto nesse caso quanto em outro em Lancashire, Inglaterra, as famílias são constituídas por pessoas que têm filhos de casamentos anteriores e que preferiram, para garantir certa autonomia, construir casas separadas para as crianças, adjacentes à construção principal.

Como prova de que a clara segregação entre os espaços público e privado deixou de ser uma evidência, Riley afirma que, invertendo um processo iniciado há aproximadamente quatro séculos, o trabalho é, atualmente, cada vez mais reintroduzido no lar, sobretudo no que o curador da exposição chama de mundo do "hipercapitalismo": de fato, em dados de 1999, cerca de vinte milhões de americanos já utilizavam suas residências como principal local de trabalho. Em vez de 
uma radical oposição entre a casa e o trabalho, tem-se, então, um fluxo contínuo e ininterrupto ligando as atividades relativas à vida quotidiana e ao trabalho. Tal contigüidade casa/trabalho está expressa em vários novos projetos arquitetônicos, quer sob a forma aberta e flexível dos lofts, quer em projetos que exploram geometrias mais complexas, topologias curvas, como a casa de Möbius, projetada por van Berkel, em Het Gooi, Holanda, e concluída em 1998. Esse projeto, em que se misturam vidro e concreto, baseiase na curiosa estrutura da fita de Möbius, uma superfície de um só lado na qual dentro e fora, exterior e interior, deixam de se opor dialeticamente, tornando-se indecidíveis, enlaçando-se continuamente para permitir uma passagem ininterrupta entre os "lados". Essa forma extremamente complexa foi utilizada para facilitar o fluxo espacial entre a vida quotidiana, o trabalho e as horas de descanso. Por conta do material utilizado e do projeto arquitetônico, a casa de Möbius configura-se como um "espaço liso", aberto e contínuo, a construção tendo sido pensada para estabelecer uma linha de continuidade entre a vida "dentro" da casa e o passeio "fora" dela, na paisagem. Outro exemplo curioso e que também parte de novos modelos matemáticos é a "Torus House", residência nova-iorquina projetada por Preston S. Cohen, que deve estar concluída este ano. Pensada para um artista, a casa, que congrega funções diversificadas (preparação de grandes telas, pintura e galeria para exposições), associa linguagens geométricas aparentemente incompatíveis, tais como formas tradicionais e formas curvilíneas derivadas do "torus".

Nessa casa, uma escada foi criada com a função explícita de ampliar a ambigüidade entre o interior e o exterior, indo direto, sem se abrir para o "interior" da casa, do estacionamento abaixo do piso até o telhado. Como afirma o próprio arquiteto, "as linhas curvilíneas e ondulações misturam os componentes individuais em uma superfície contínua que se assemelha aos aspectos da paisagem que está além" ${ }^{10}$

Como exemplo de moradia em que a estrutura aberta do loft se adapta à indistin- ção entre espaços de vida quotidiana e atividades de trabalho, há o apartamento Lipschutz/Jones, em Manhattan, projetado por Frank Lupo e Daniel Rowen e concluído em 1988. Como ambos os proprietários trabalham no mercado financeiro de Wall Street, por conta da globalização das bolsas de valores seus horários de trabalho não podem ser fixados rigidamente, tornando-se, de fato, um fluxo contínuo. Por isso, o escritório invade a casa toda, em certo sentido, pois, como observa Riley, ela se "assemelha a um panóptico": as telas digitais, com suas luzes intermitentes, podem ser vistas de diversas áreas do loft. Corrigindo o curador, acrescento que, nesse caso, há um panóptico invertido, já que não se trata de uma estrutura utilizada para uma vigilância contínua, mas, no sentido contrário, para a recepção ininterrupta de uma multiplicidade de informações simultâneas em tempo real, que captura o olhar do morador a todo momento e em qualquer situação: portanto, não se trata aqui de um olho humano que vigia, mas da vigília constante de um olhar tragado por imagens produzidas digitalmente. ${ }^{11}$ Vale notar, de passagem, de que forma certos setores intelectuais e artísticos norte-americanos têm-se apropriado recentemente, nem sempre com muita pertinência, da produção teórico-filosófica francesa, de viés radicalmente crítica, como é o caso de Foucault ou de Deleuze (no caso, por exemplo, da referência a "espaços lisos"). Ainda nessa residência, há seis outras telas espalhadas pelos diversos espaços da casa, disseminando continuamente informação em tempo real tanto junto ao espelho do banheiro, de forma a poder ser consultada enquanto o morador faz sua barba, quanto próximo à cama, de modo a poder ser visível ao acordar, pois se trata de um regime de trabalho contínuo, ininterrupto, na verdade interminável.

Nesse último exemplo, evidencia-se de que maneira a casa tende a se tornar, nas palavras de Terence Riley, "uma estrutura permeável, apta a receber e a transmitir imagens, sons, textos e informação em geral". ${ }^{12}$ Como outro expressivo exemplo dessa tendência, além do apartamento Lipschutz/Jones, no 

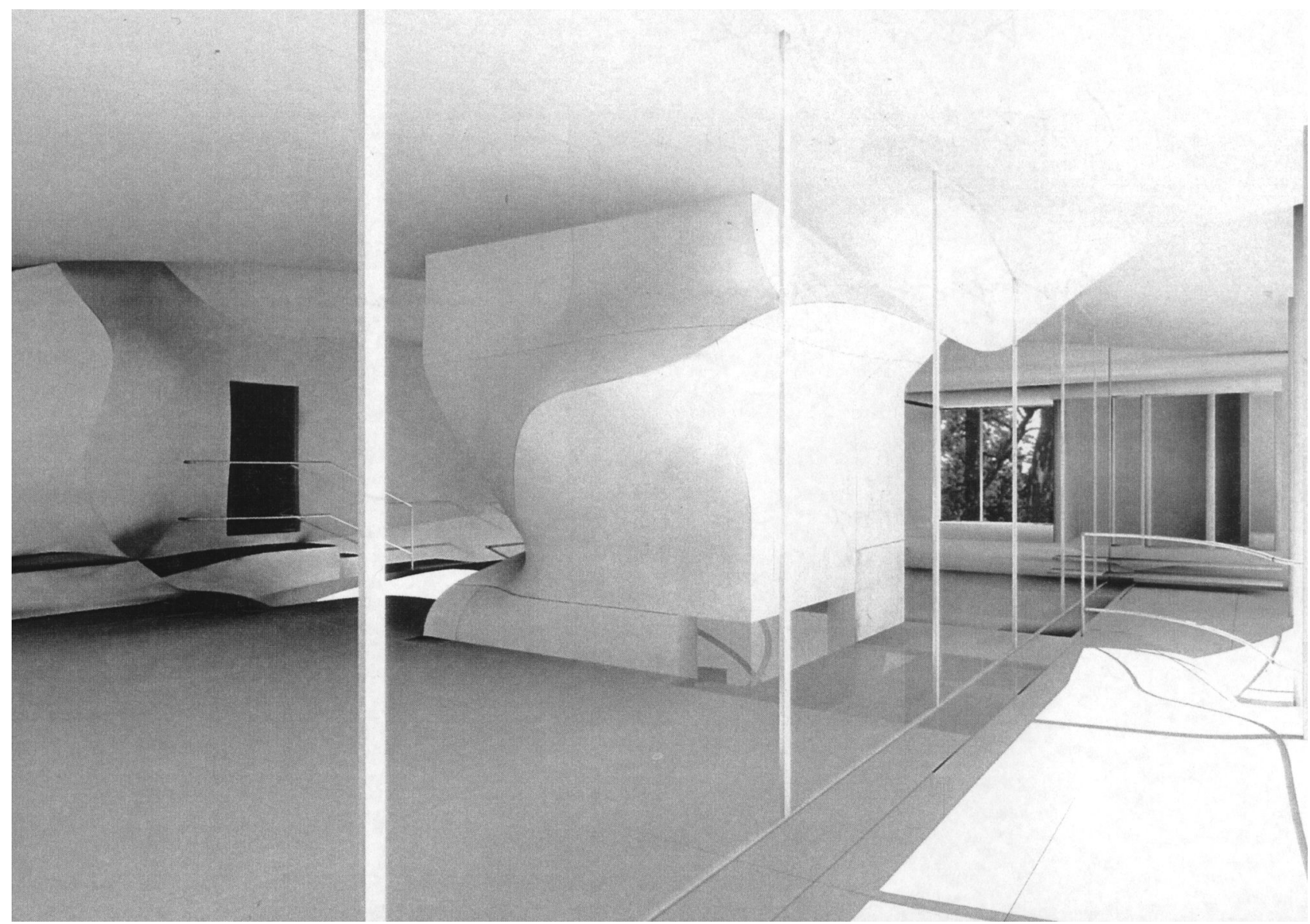

Presnton Scott Cohen: Forms House, New York. (imagens geradas por computador). Término previsto: 2001.

qual, como vimos, telas digitais disponibilizam informação financeira por todo o loft, alertando os proprietários sobre as flutuações das bolsas de valores internacionais, a exposição mostra o projeto de uma casa a ser finalizada este ano, construída entre vinhedos do Napa Valley, na Califórnia, desenhada por Jacques Herzog e Pierre de Meuron em 19971998: trata-se da residência Kramlich, que também funciona como uma coleção de mídia. Como apresenta o catálogo da exposição, "sua estrutura é concebida tanto como um lar para um casal quanto como um local para exibição de sua grande coleção de arte eletrônica", caracterizando-se pela ambigüidade intencional entre a casa e a mídia-instalação. ${ }^{13}$ Nessa residência, mesclam-se, de modo radical, o físico e o imaterial: as próprias divisórias ondulantes que definem os cômodos também são telas nas quais vídeos, filmes e arte digital podem ser continuamente projetados. Como observam os arquitetos, a concepção de espaço "foi planejada para permitir que o exterior, o interior e as imagens projetadas pelos artistas fluam umas para as outras".

Já em outro projeto, intitulado "casa lenta" ("slow house"), de autoria de Diller e Scofidio - uma residência de fim de semana ainda não construída em Long Island, Nova York, e desenhada para um jovem colecionador de arte e empresário japonês -, as tecnologias do virtual têm função diversa. A parte detrás da casa, que oferece uma vista para a baía, é totalmente envidraçada; como significativamente descrevem os arquitetos, ela foi "concebida como um aparelho para produzir vista. Simplesmente, a casa é uma porta que leva até uma janela, uma entrada física para uma partida ótica". ${ }^{14}$

Uma câmera de vídeo, instalada acima da casa, captura a paisagem e a transmite para um monitor suspenso diante da janela envidraçada, podendo, desse modo, duplicar digitalmente a vista "natural" da água, o que permite que sua imagem seja retransmitida sempre que se desejar. Segundo os arquitetos, "a vista pode ser gravada e diferida [...], o dia repassado à noite, o tempo bom re- 
transmitido quando estiver fazendo tempo ruim. A vista é também portátil, podendo ser transmitida para diferentes locais na casa ou mesmo para a residência principal, na cida$\mathrm{de}^{\prime \prime} \cdot{ }^{15}$

Ainda conforme os arquitetos, tanto a janela envidraçada quanto a tela de vídeo são pensadas como mediações para o olhar, na medida em que ambas emolduram, investindo algo de valor, e domesticam, de certo modo, a natureza. ${ }^{16}$

Podemos observar, nesse caso, a tendência à substituição da "paisagem", em sua concepção tradicional, pela imagem digitalizada, de alta definição, passível de ser manipulada e deslocada, que tende a ser cada vez mais presente no "gosto" e nos novos hábitos perceptivos da contemporaneidade, bem como a expressiva obsolescência do próprio conceito de "natureza". Como já apontava Paul Virilio, as janelas e certa velocidade de deslocamento sempre funcionaram como recortes perceptivos, o que está implícito na radicalização, efetuada pelos arquitetos, da identificação entre a janela - tomada como tela convencionalmente naturalizada - e a tela propriamente dita. Tudo se passa como se, paulatinamente, o referencial passasse a ser a realidade digitalizada que as novas tecnologias produzem. Resta ainda observar, no caso específico da "slow house", que seu proprietário - um empresário japonês - parece prezar sobremaneira a captura de imagens. A casa secundária é identificada a um tempo de fruição, a uma ruptura na tensão e na aceleração da vida urbana, permitindo uma temporalidade "ralentada" que se enuncia no próprio título do projeto arquitetônico.

A "casa virtual" tem sido desenvolvida e pensada por vários arquitetos também para atender às necessidades mais prosaicas da vida quotidiana. Se, no caso da residência Kramlich, as superfícies interiores são destinadas a servir como telas para a projeção da coleção de arte digital de seus proprietários, em outros projetos, tal como a "casa digital" desenhada em 1998 por Gisue Hariri e Mojgan Hariri para a revista House Beautiful, para demonstrar o impacto potencial das novas tecnologias eletrônicas sobre a moradia, o aparato tecnológico ganha outras funções. Nesse projeto, tanto as superfícies interiores quanto as exteriores foram concebidas como "peles inteligentes" aptas a apagar "a distinção entre o computador e a arquitetura, e realizar várias funções para auxiliar ou incrementar a vida diária". ${ }^{17}$ Tal casa possui partes totalmente moduláveis, com cômodos que podem ser "plugados" ou "desplugados" para servir a novas orientações programáticas ou para se adaptar a novas situações domésticas. Seu "centro", entretanto, não se restringe a uma função meramente estrutural, uma vez que as paredes principais são feitas de telas de cristal líquido, permitindo, por exemplo, que um chefe de cozinha virtual da preferência dos moradores auxilie na preparação da comida, ou que os residentes conversem com amigos que moram bem distante, recebendo-os, na sala de estar, em uma visita virtual. O olhar poderá percorrer diversos níveis de realidade, deslizando, sem solução de continuidade, de partes da própria casa para a paisagem ou para as imagens nas paredes. Nesse sentido, os computadores e as imagens digitalizadas não foram pensados como uma presença discreta, mas como superfícies e dispositivos interativos. Como afirma o curador da exposição, aproximando-se de certa abordagem filosófica bastante em voga contemporaneamente, "como um receptor e transmissor de informação, a casa também se torna uma extensão da mente". ${ }^{18}$

Além do aspecto contínuo, flexível, permeável e interativo dessas novas maneiras de morar, outro elemento presente nos projetos das "casas não-privadas" pode ser ainda mais evidentemente articulado à falência atual da dialética dentro-fora e da antinomia correlativa entre privado e público: a transparência, a "nudez", em radical oposição ao ideal moderno de "privacidade absoluta", de vida aconchegante entre opacas quatro paredes. Não se trata apenas de uma "transparência virtual", ou seja, da intromissão cada vez mais acentuada de 


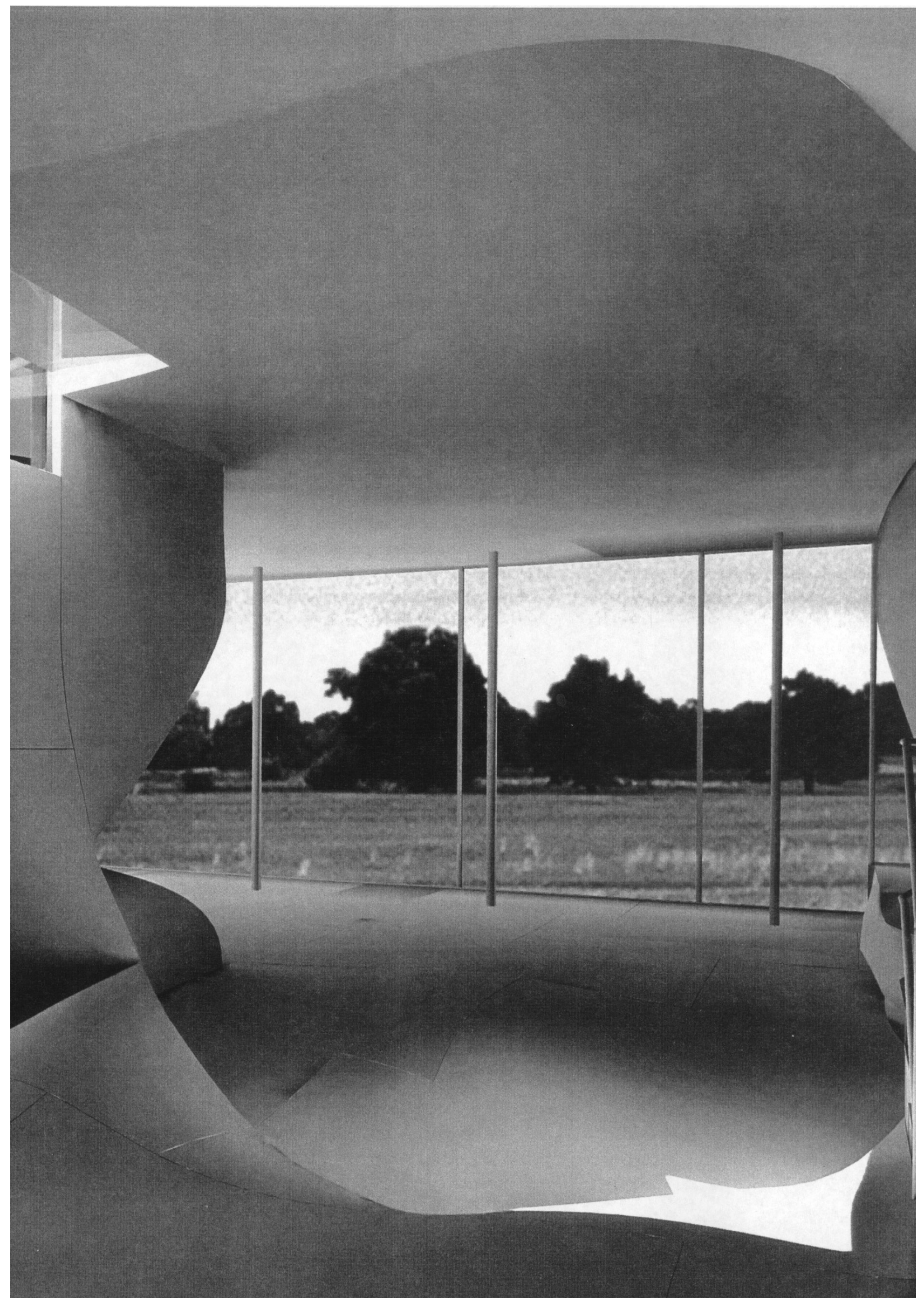

Forms House, New York. (imagem gerada em computador, finalização da construção: 2001). 
mídia eletrônica nas casas e na vida quotidiana, conforme evidenciado na "casa digital" acima mencionada. Trata-se de casas literalmente transparentes, em áreas urbanas densamente povoadas, não necessariamente planejadas para pessoas de alta renda. Em Amsterdã, por exemplo, em um novo bairro residencial (Borneo Sporenburg), há dois projetos desse tipo. Um deles foi concebido como um espaço "contínuo" que vai se estendendo para cima, por patamares assimétricos, como se fosse um "loft vertical"; o fluido espaço interior conectase com o lado de fora, seja através de um pequeno jardim no térreo, seja por meio de uma sacada interior no segundo piso ou ainda por um terraço no telhado, acima do quarto. Como os patamares não coincidem de todo, há desnível de pé-direito em cada local e até mesmo uma parte com teto bem alto, o que acentua a sensação de abertura, além, obviamente, das fachadas totalmente feitas de vidro transparente, que dão para a rua e para o canal. Como comenta o catálogo da exposição, à diferença de projetos anteriores de "casas de vidro" ou de residências coladas umas às outras em bairros com grande densidade populacional, a casa é "altamente transparente e potencialmente aberta à visão pública". ${ }^{19}$ Eis como um dos arquitetos responsáveis pelo projeto, Winy Maas, do renomado grupo MVRDV, justifica a verdadeira nudez da casa, associada de modo explícito à expansão atual da "sociedade do espetáculo", já diagnosticada em meados dos anos 60 por Guy Débord ${ }^{20}$ :

"Colocar o interior, mesmo o nosso, em exposição parece um tópico bastante moderno. Pode ser perverso, mas tem semelhanças com a mistura entre o público e o privado nos dias de hoje: passar pela calçada e ouvir a conversa amorosa do vizinho que fala no telefone com a namorada, a maneira como as pessoas mostram sua privacidade na televisão a fim de chamar a atenção. Em tal contexto, as antigas limitações entre privacidade e publi-

\section{cidade parecem ser irrelevantes". ${ }^{21}$}

Em um projeto de casa dupla (199597) concebido, em Utrecht, Holanda, por B. Mastenbroek e MVRDV, essa ausência de limitação se expressa de outro modo: os arquitetos não separaram as casas coladas como tradicionalmente se faz, por meio de uma só parede reta, mas criaram uma parede divisória em ziguezague, de modo a fazer com que os moradores experimentassem, de modo mais palpável, a presença dos vizinhos e os próprios espaços comuns do edifício por eles divididos.

Esse tipo irregular de divisória vai evidentemente de encontro à sensação de "privacidade" suscitada pelas tradicionais paredes retas, que tornavam mais "invisível", praticamente imperceptível, a presença contígua do vizinho de andar. Em outro projeto, criado por Michael Bell e planejado para estar concluído no ano passado - a "casa de vidro @ 20"-, também foi explorada a transparência literal, em um bairro de rica tradição cultural, mas de baixa renda, em Houston, contrariando a tradição histórica que vincula o uso de transparências, de fachadas de vidro a certo nível de sofisticação e de opulência.

Ao mencionar o fato de a casa de vidro possibilitar a revelação tanto de sua estrutura quanto da vida dos moradores, Bell alude às qualidades visionárias do vidro, associadas à transparência, à abertura, à igualdade e à liberdade. Diante da possível crítica à "profanação" da privacidade por conta do uso desse material, responde com a seguinte reflexão: "Por que um grupo invisível de pessoas escolheria viver por detrás de paredes, em vez de revelar suas vidas?" 22 Em outro projeto de uma residência na capital holandesa, ainda não construída - a "Hague Villa" -, concebida como moradia e simultaneamente local de trabalho, os principais espaços ocupam um volume de vidro de três andares. É essa parte totalmente transparente que foi programada para as principais atividades diárias e de trabalho. 
Eis como o arquiteto, Bernard Tschumi, comenta a permeabilidade virtual e literal da casa, associando o volume de vidro não apenas à transitividade visual mas, igualmente, à concepção de uma moradia como um dispositivo de recepção e de transmissão de informação eletrônica, o que, evidentemente, demonstra a total obsolescência da antiga distinção entre o público e o privado:

"A aparência de permanência (i.e., edifícios são sólidos; são feitos de aço, de concreto, de tijolos, etc.) é cada vez mais desafiada pela representação imaterial de sistemas abstratos (televisão e imagens eletrônicas). A casa deve ser vista como uma extensão de eventos urbanos e como uma pausa momentânea na transferência digital de informação. Os limites entre a sala e o escritório [...] expandem-se para além das divisas da propriedade, assim como estas últimas são minadas pelos aparelhos eletrônicos de uso diário". ${ }^{23}$

Talvez o exemplo mais expressivo da transparente nudez da casa que se expande para além de seus limites, fundindo-se com uma densa paisagem urbana e com o espaço antes associado ao público, é a residência de três andares, de paredes de cortina de pano, já construída, projetada por Shigeru Ban para uma família em Itabashi, um bairro densamente povoado de Tóquio. Sua fachada é composta por dois elementos: painéis de vidro transparente e cortinas de tecido do tamanho de velas de barco, ambos podendo ser totalmente abertos, desnudando o interior da casa. Conforme descrito no catálogo,

“a cortina [...] pode ser aberta e fechada para alterar a vista e determinados efeitos do ambiente, tais como a luz e o vento. Quando a cortina está fechada à noite, a casa parece resplandecer por dentro; quando está completamente aberta duranShigeeru Ban: Curtain Wall House. Tokyo, 1995. te o dia, os moradores parecem, assim 
como todo o resto, estar vivendo no deque de um navio" ${ }^{24}$

Evidentemente, uma casa desse tipo, além de corroer, de modo radical, os limites que costumavam separar o público do privado, será habitada por subjetividades que não mais privilegiam, como função fundamental da moradia, a idéia moderna de "privacidade". E de fato, segundo o curador da exposição, a total exposição possibilitada por esse tipo de casa chega a surpreender até mesmo aqueles que já vivem em outras modalidades de casas de vidro.

Há ainda outros exemplos de "nudez" da casa que exploram a transparência não apenas em seus sentidos virtual e literal, como vimos anteriormente, mas também em relação ao próprio espaço interior. Tal é o caso, por exemplo, de casas em que a tecnologia permite a cada pessoa auto-observar-se, como no ambiente doméstico concebido por Kipping, no qual um "espelho eletrônico", totalmente diverso dos tradicionais espelhos de banheiro, é composto por quatro câmeras de vigilância posicionadas de forma a possibilitar uma autovigilância mais integral. ${ }^{25}$ Trata-se, nesse caso, de uma verdadeira exacerbação da função panóptica das novas tecnologias, oferecendo àquele que quer se esquadrinhar uma multiplicidade de imagens produzidas por máquinas de visão não mais analógicas ao olhar humano.

Resta ainda, nesse mesmo sentido, mencionar o projeto de Alex van Es, analista de sistemas da cidade de Apeldoorn, Holanda. Tendo conectado à Internet tanto a campainha da porta quanto sua geladeira, seu banheiro, o despertador e as seis câmeras espalhadas por toda a casa, van Es disponibiliza, para a observação pública, vários detalhes íntimos de sua vida e consegue controlar, por exemplo, o número de vezes que abre a geladeira, o que come, além de quantificar quantas vezes vai ao banheiro, quantas visitas recebe, etc.

Aqueles que visitam seu web site podem consultar todos esses dados e até mesmo programar a música que irá acordá-lo no dia seguinte. Constitui-se, assim, um tipo de interatividade em ausência, mediada por tecnologias que permitem certa forma de contato, sem precisar alterar o afastamento físico dos corpos. Terence Riley acrescenta, como interessante comentário entre parênteses, que talvez os holandeses, que praticamente inventaram a noção de privacidade doméstica (bastante presente em sua rica produção pictórica), parecem ser os que atualmente menos a prezam. ${ }^{26}$ Observa, ainda, que, em um mundo de crescente isolamento, de verdadeiro insulamento nas megalópoles, esse convite ao público para que acompanhe em detalhe os aspectos mais íntimos e triviais das rotinas domésticas sugere que o olhar interativo dos mídia pode representar não apenas uma intromissão, mas igualmente uma presença reconfortante.

Os projetos de moradias, apresentados na exposição do MOMA, têm, portanto, como características comuns, o fato de em geral se configurarem como espaços contínuos, fluidos, permeáveis, abertos, transparentes e flexíveis, indicando, de modo por vezes evidente, certo esvaziamento da dialética público/privado, da dicotomia dentro/fora, na sociedade tecnológica contemporânea, processo apontado, a partir de outros contextos, pelos autores de que estes breves comentários partiram. Tais mutações remetem à paulatina instalação de novos modos de sentir, de perceber e de experimentar o mundo, cujas implicações estamos longe de poder diagnosticar em toda a sua extensão.

Nesse sentido, cabe explorar algumas pistas que possibilitem a tematização das mudanças atualmente em curso, levando evidentemente em conta a extrema complexidade dos processos, bem como a simultaneidade de diferentes tempos históricos que coexistem hoje no mundo.

Não se pretende, assim, tomar como norma ou mesmo generalizar o que pudermos inferir da observação de projetos arquitetônicos de ponta, tais como aqueles expostos na exposição do MOMA. Trata-se de utilizá-los como sintomas e indicadores precisos de certas mutações próprias à passagem do 
século XX para o XXI em regiões mais centrais do "império".

Tal é o interesse e, ao mesmo tempo, o limite deste tipo de pesquisa. A crise da maneira de ser, de viver e de pensar modernas e a "onicrise" inerente ao movimento do próprio capitalismo, identificadas por Michael Hardt a partir de Deleuze ${ }^{27}$, refletem-se, sob diversos aspectos, nos projetos arquitetônicos acima descritos.

Novos modelos matemáticos, mais complexos, passam a ser convocados, como o da fita de Möbius, que inviabiliza a oposição entre dentro e fora, entre interior e exterior, parecendo corresponder a um diagrama apto a cartografar uma situação contemporânea que se apresenta atravessada por diversas temporalidades, por simultaneidades não passíveis de homogeneização, solicitando inventivas e novas alternativas •

\section{Notas}

1 Sennett, Richard, 0 declínio do homem público (as tiranias da intimidade), São Paulo, Companhia das Letras, 1999.

2 Foucault, Michel, História da sexualidade I (A vontade de saber), Rio de Janeiro, Graal, 1980. Para a análise do poder aqui referida, cf., igualmente, os livros A verdade e as formas jurídicas (Rio de Janeiro: Nau Ed., 1996) e Vigiar e punir (Petrópolis: Vozes, 1977).

3 Cf. História da sexualidade I, op. cit., p. 59.

4 Cf., a esse respeito, as importantes contribuições, dentre outros, de Robert Kurz (por exemplo, em Os uiltimos combates, Petrópolis, Vozes, 1998) e de François Chesnais (em A mundialização do capital, São Paulo, Xamã, 1996).

5 Cf. Hardt, Michael, "A sociedade mundial de controle", in Gilles Deleuze: uma vida filosófica, São Paulo, Ed. 34, 2000, p. 357372 (minha tradução), e Negri, Antonio e Hardt, Michael, o polêmico livro Empire, publicado em 2000 pela Universidade de Harvard.

6 Trata-se de um grupo organizado por Jurandir Freire Costa (IMS/UERJ), que se reuniu em Itatiaia, de 17 a 19 de novembro de 2000, tendo, como tema central das discussões, a questão da vontade e, mais especificamente, da fraqueza da vontade.

7 Riley, Terence, The Un-private house, Nova York, The Museum of Modern Art (MOMA), 1999, pp. 9-36.

$8 \quad$ Ibid., p. 18.

9 Ibid., p. 19, igualmente para os exemplos a seguir.

10 Ibid., p. 104.

11 A respeito da política da percepção vinculada à contemporaneidade, cf. o instigante livro de Christian Ferrer, Mal de ojo (el drama de la mirada), Buenos Aires, Ed. Colihue, 1996, cujo pathos sombrio se alia à radicalidade e rica densidade da visada crítica.

12 Ibid., p. 11.

13 Ibid., p. 48, bem como para as descrições que se seguem.

14 Ibid., p. 52.

15 Ibid., p. 13.

16 Ibid, p. 52.

17 Ibid., p. 13.

18 Ibid, p. 36.

19 Ibid., p. 62.

20 Cf. Guy Débord, La société du spectacle, Paris, Gallimard, 1992.

21 Ibid., p. 16.

22 Ibid., P. 64.

23 Ibid., pp. 16 e 68.

24 Ibid., p. 72.

25 Ibid., pp. 16-17.

26 Ibid., p. 17.

27 Cf. Hardt, Michael, "A sociedade mundial de controle", op. cit. 